Article

\title{
Effect of a Novel Flame Retardant on the Mechanical, Thermal and Combustion Properties of Poly(Lactic Acid)
}

\author{
Mingjun Niu, Zhongzhou Zhang, Zizhen Wei and Wanjie Wang * \\ College of Materials Science and Engineering, Zhengzhou University, Zhengzhou 450001, China; \\ niumj@zzu.edu.cn (M.N.); zhangzhongzhou2010@163.com (Z.Z.); weizizhen0101@163.com (Z.W.) \\ * Correspondence: wwj@zzu.edu.cn
}

Received: 11 September 2020; Accepted: 9 October 2020; Published: 19 October 2020

\begin{abstract}
Poly(lactic) acid (PLA) is one of the most promising biobased materials, but its inherent flammability limits its applications. A novel flame retardant hexa-(DOPO-hydroxymethylphenoxydihydroxybiphenyl)-cyclotriphosphazene (HABP-DOPO) for PLA was prepared by bonding 9,10dihydro-9-oxy-10-phosphaphenanthrene-10-oxide (DOPO) to cyclotriphosphazene. The morphologies, mechanical properties, thermal stability and burning behaviors of PLA/HABP-DOPO blends were investigated using a scanning electron microscope (SEM), a universal mechanical testing machine, thermogravimetric analysis (TGA), differential scanning calorimetry (DSC), limiting oxygen index (LOI), vertical burning (UL-94) and a cone calorimeter test (CCT). The LOI value reached $28.5 \%$ and UL-94 could pass V-0 for the PLA blend containing $25 \mathrm{wt} \%$ HABP-DOPO. A significant improvement in fire retardant performance was observed for PLA/HABP-DOPO blends. PLA/HABP-DOPO blends exhibited balanced mechanical properties. The flame retardant mechanism of PLA/HABP-DOPO blends was evaluated.
\end{abstract}

Keywords: flame retardant; poly(lactic acid); mechanical properties; blends

\section{Introduction}

Plastics originated from petrochemicals cause serious environmental problems due to their non-degradable nature. Biodegradable plastics are a promising replacement for conventional synthetic plastics. Poly(lactic acid) (PLA) is an attractive biopolymer for packaging engineering [1], biomedical fields [2], automobile engineering [3,4] and the electricity industry [5] because of its biodegradability, non-toxicity, high optical transparency and good mechanical, thermal and electrical properties $[6,7]$. However, PLA has some shortcomings such as high flammability and poor toughness, which can easily lead to fire accidents and limit its further applications. Therefore, investigations into PLA for its excellent thermal, mechanical and flame retardant properties have attracted more and more attention $[8,9]$.

In recent years, several approaches have been applied to improve the flame retardant properties of PLA [10-12]. Non-halogen flame retardants such as phosphorus-containing silsesquioxane [13-15], intumescent flame retardants [16-20] and nitrogen phosphorus flame retardants [21-23] were employed to overcome this drawback. For example, Chen et al. [24] evaluated the efficiency of a novel flame retardant heax-( $N, N^{\prime}, N^{\prime \prime}$-tris-(2-amino-ethyl)-(1,3,5)triazine-2,4,6-triamine)cyclotriphosphazene (HTTCP) for PLA. They found that when the concentration of HTTCP was $25 \mathrm{wt} \%$, the blends showed a $25.2 \%$ value of limiting oxygen index (LOI) and a lower peak of heat release rate (pk-HRR) compared with neat PLA under the same measurement conditions. Xi et al. [22] characterized flame retardancy, using a cone calorimeter test, and dripping properties of PLA/10 wt $\%$ TGIC-DOPO blend. The results 
showed that the flame retardant promoted breaking up and dripping early, released fragments with quenching and dilution effects, and improved the flame retardancy of PLA. Gu et al. [23] synthesized multi-walled carbon nanotubes (MWCNT)-DOPO-OH with a core-shell nanostructure by a three-step process. MWCNT-DOPO-OH was introduced into aluminum hypophosphite (AHP)/PLA flame retardant systems via melt blending to improve both flame retardancy and mechanical properties. Apart from types of organic hydroxide multi-walled carbon nanotubes and sepiolite nanoclay, biofibers $[25,26]$ can also greatly elevate LOI, dripping, vertical burning (UL-94) and thermal properties of PLA blends. Although many types of flame retardants can improve effectively the flame retardancy of PLA, the mechanical properties of PLA decrease greatly due to high loading of flame retardants.

Recently, a novel flame retardant DOPO-HQ has received considerable attention and exhibits prominent fire-resistant properties in epoxy resins and polyurethane foam [27]. DOPO-HQ possesses high thermal properties, chemical endurance and water resistance because of its rigid aromatic structures and stable $\mathrm{P}-\mathrm{O}-\mathrm{C}$ bond. On the other hand, $\mathrm{DOPO}-\mathrm{HQ}$ can degrade to produce phosphorous-containing radicals which further prevent polymers from burning by scavenging $\mathrm{H} \cdot$ and $\mathrm{OH}$. radicals in gas phase [28].

In this paper, a novel functionalized flame retardant, HABP-DOPO, was designed and synthesized by substitution reaction based on cyclotriphosphazene, dihydroxybiphenyl and DOPO. HABP-DOPO was incorporated into the PLA matrix to prepare fire-resistant PLA/HABP-DOPO blends via a melt blending method. The chemical structure of HABP-DOPO was characterized by nuclear magnetic resonance (NMR), Fourier transform infrared spectroscopy (FTIR) and elemental analysis (EA). The thermal properties and fire-resistant performance of PLA/HABP-DOPO blends were conducted by TGA, DSC, LOI, cone colorimetry and UL-94 vertical combustion tests. The flame retardant mechanism and mechanical properties of blends were also investigated.

\section{Materials and Methods}

\subsection{Materials}

PLA (4032D, $0.3 \mathrm{~g} / 10 \mathrm{~min}$ ) was purchased from Nature Works LLC (Minnetonka, MN, USA), the flame retardant HABP-DOPO was synthesized and hexachlorocyclotriphosphazene (HCCP), p-hydroxybenzaldehyde, 2,2'-biphenyldiol and DMF were purchased from Shanghai Aladdin Bio-Chem Technology Co., Ltd. (Shanghai, China).

\subsection{Synthesis of the Flame Retardant HABP-DOPO}

The synthetic route is illustrated in Figure 1. A mixture solution of $29 \mathrm{mmol} \mathrm{HCCP}, 29 \mathrm{mmol}$ 2,2'-dihydroxybiphenyl and $70 \mathrm{mmol} \mathrm{K}_{2} \mathrm{CO}_{3}$ (Aladdin, Shanghai, China) in $100 \mathrm{~mL}$ acetone was stirred at room temperature for $15 \mathrm{~min}$. The filtrate was steamed in a vacuum, then the residue was extracted with $\mathrm{CH}_{2} \mathrm{Cl}_{2}$ (Aladdin, Shanghai, China). Recrystallization from $\mathrm{CH}_{2} \mathrm{Cl}_{2} /$ petroleum ether (Aladdin, Shanghai, China) gave the pure product $\mathrm{C}_{12} \mathrm{H}_{8} \mathrm{O}_{2} \mathrm{C}_{14} \mathrm{~N}_{3} \mathrm{P}_{3}$ [29]. FTIR: 1438.46, 1477.09, 1502.04 (benzene ring), 1176.44, $1209.64(\mathrm{P}=\mathrm{N})$ and $756.40 \mathrm{~cm}^{-1}(1,2$ ortho substitution on the benzene

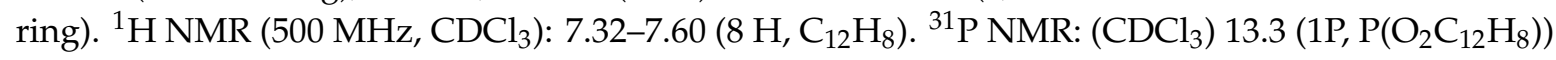
and $25.2(2 \mathrm{P}, \mathrm{P}-\mathrm{Cl})$. EA for $\mathrm{C}_{12} \mathrm{H}_{8} \mathrm{O}_{2} \mathrm{C}_{14} \mathrm{~N}_{3} \mathrm{P}_{3}$ : C, 31.3; $\mathrm{H}, 1.7$ and $\mathrm{N}, 9.1$.

In $150 \mathrm{~mL}$ tetrahydrofuran (THF) (Aladdin, Shanghai, China), $4.26 \mathrm{mmol} \mathrm{C}_{12} \mathrm{H}_{8} \mathrm{O}_{2} \mathrm{C}_{14} \mathrm{~N}_{3} \mathrm{P}_{3}$ was dissolved and slowly added to a mixture solution of P-hydroxybenzaldehyde and $\mathrm{K}_{2} \mathrm{CO}_{3}$. The solution was stirred for half an hour at room temperature and heated to $80^{\circ} \mathrm{C}$ for $24 \mathrm{~h}$ to obtain intermediate HABP. FTIR: 1704.01 (the $\mathrm{C}=\mathrm{O}$ of the $-\mathrm{CHO}$ ), 2741.55, 2844.26 (the $\mathrm{C}-\mathrm{H}$ of the $-\mathrm{CHO}$ ), 1178.56 (the vibration peak of the aromatic aldehyde), 521.00 and $594.00 \mathrm{~cm}^{-1}(\mathrm{P}-\mathrm{Cl})$ disappeared. ${ }^{1} \mathrm{H}$ NMR (500 MHz, $\left.\mathrm{CDCl}_{3}\right)$ : $6.80-7.58\left(8 \mathrm{H}, \mathrm{C}_{12} \mathrm{H}_{8}\right)$ and 7.83-7.87 (16H, C6H4). ${ }^{31}$ PNMR: $\left(\mathrm{CDCl}_{3}\right), 7.77,8.35$ (2P, $\left.\mathrm{P}\left(\mathrm{O}_{2} \mathrm{C}_{7} \mathrm{H}_{5}\right)\right)$ and 23.40-24.57 (1P, $\mathrm{P}\left(\mathrm{O}_{2} \mathrm{C}_{12} \mathrm{H}_{8}\right)$ ). EA for HABP: $\mathrm{C}, 59.6 ; \mathrm{H}, 3.5$ and $\mathrm{N}, 5.2$.

In a $500 \mathrm{~mL}$ three-necked flask equipped with a magnetic stirrer, a condenser and a nitrogen apparatus at $120^{\circ} \mathrm{C}, 26.4 \mathrm{mmol}$ DOPO was dissolved in $100 \mathrm{~mL} \mathrm{~N}, \mathrm{~N}$-Dimethylformamide (DMF). 
To the mixture, $4 \mathrm{mmol} \mathrm{HABP}$ was added and maintained stirred at $140{ }^{\circ} \mathrm{C}$ for $10 \mathrm{~h}$. Finally, a large amount of ice water was fed into the solution and white precipitate was obtained. The precipitate was washed three times with dry ethanol/toluene mixed solution and dried in a vacuum for $24 \mathrm{~h}$ at $80^{\circ} \mathrm{C}$. FTIR: $3424.54(-\mathrm{OH}), 756.24,946.96(\mathrm{P}-\mathrm{O}-\mathrm{Ph}), 1209.64(\mathrm{P}=\mathrm{N})$ and $2437.55 \mathrm{~cm}^{-1}(\mathrm{P}-\mathrm{H})$ disappeared. ${ }^{1} \mathrm{H}$ NMR (500 MHz, DMSO): 5.19-5.40 (H, C-H), 6.46-6.94 (H,-OH) and 7.01-8.04 (H, DOPO). ${ }^{31} \mathrm{P} \mathrm{NMR}$ (DMSO): 8.83, 9.40 (1P, $\mathrm{P}\left(\mathrm{C}_{12} \mathrm{H}_{8}\right)$ ), 25.06 and 31.50 (2P, P(DOPO)). EA for HABP-DOPO: C, 12.7; $\mathrm{H}, 4.3$ and $\mathrm{N}, 2.5$.

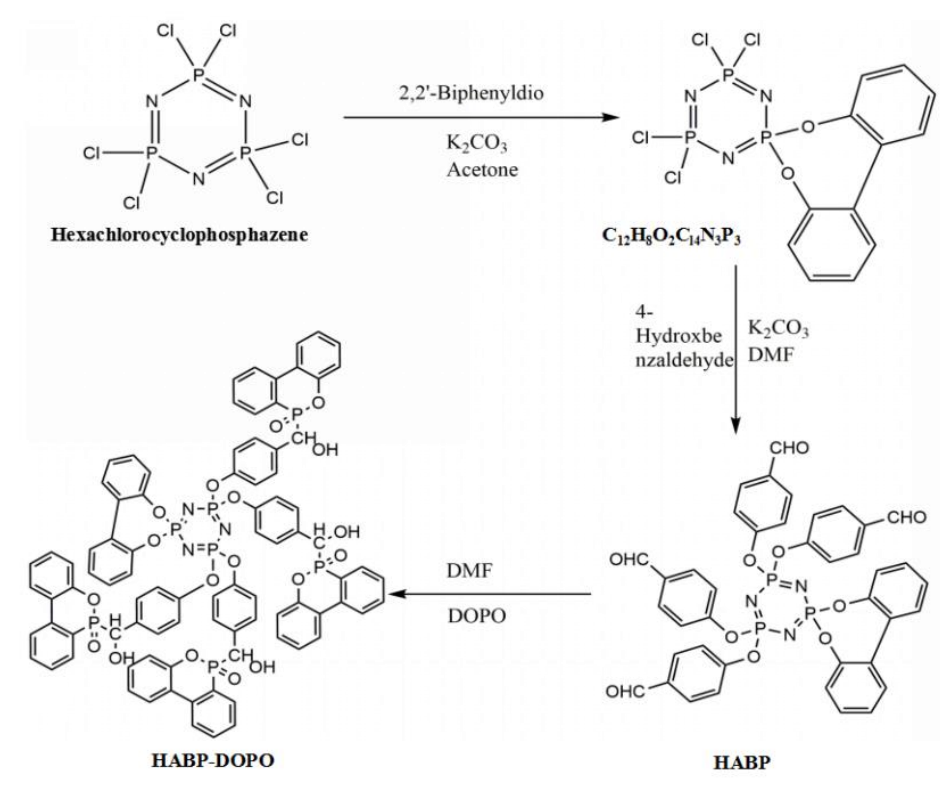

Figure 1. Preparation route and structure of HABP-DOPO.

\subsection{Preparation of Flame Retardant PLA Blends}

PLA was dried in a TY-ZK-1 vacuum (Taiyu, Suzhou, China) at $80{ }^{\circ} \mathrm{C}$ for $12 \mathrm{~h}$. According to the mixing ratio, PLA and HABP-DOPO were blended in a melt mixer (Shanghai S.R.D. LB-100, China) at $180^{\circ} \mathrm{C}$ and $60 \mathrm{rpm}$ for $10 \mathrm{~min}$. The mixture was hot-pressed into a sheet specimen under $5 \mathrm{MPa}$ at $190^{\circ} \mathrm{C}$.

\subsection{Measurements}

FTIR spectra were recorded using a Thermo Nicolet iS50 spectrometer (Thermo Fisher Scientific inc.; Waltham, MA, USA) in the range of $500-4000 \mathrm{~cm}^{-1}$ (KBr disk). ${ }^{1} \mathrm{H}$ NMR and ${ }^{31} \mathrm{P}$ NMR data were obtained using a Bruker $400 \mathrm{MHz}$ WB Solid-State NMR Spectrometer (Bruker, Billerica, MA, USA). Elemental analysis data were obtained using an instrument of Vario EL cube (Elementar, Hamburg, Germany). TGA was carried out on an STA 449 F3 Jupiter analyzer (Netzsch GmbH, Germany) under $\mathrm{N}_{2}$ atmosphere at a heating rate of $10^{\circ} \mathrm{C} / \mathrm{min}$ from room temperature to $800{ }^{\circ} \mathrm{C}$. Thermal behavior of the samples was studied with a NETZSCH-DSC 200F3 (Netzsch GmbH, Germany) instrument under nitrogen atmosphere. Samples were firstly heated from 30 to $200{ }^{\circ} \mathrm{C}$ at a rate of $10^{\circ} \mathrm{C} / \mathrm{min}$, held at $200{ }^{\circ} \mathrm{C}$ for $5 \mathrm{~min}$, cooled to $30^{\circ} \mathrm{C}$ at the cooling rate of $10{ }^{\circ} \mathrm{C} / \mathrm{min}$ and heated again to $200{ }^{\circ} \mathrm{C}$ at the same rate.

LOI values were performed on a HC-2 (Jiangning Analysis Instrument Co., Nanjing, China) with $100 \times 10 \times 3 \mathrm{~mm}$ sheets according to ASTM D2863-97. A UL-94 burning test was carried out on a ZY6017 instrument (Zonsky Instrument CO., Ltd., Dongguan, China) with $125 \times 13 \times 4 \mathrm{~mm}$ sheets according to the UL-94 standard method. The fire test was performed on an FTT cone calorimeter (FTT Ltd., East Grinstead, UK) with $100 \times 100 \times 3 \mathrm{~mm}$ sheets at a heat flux of $50 \mathrm{~kW} / \mathrm{m}^{2}$ in the horizontal configuration according to ISO 5660. The morphologies of the char after a cone calorimeter test was 
observed using JEOL JSM-7500F field emission SEM (JEOL, Tokyo, Japan). The surfaces were sputtered with a thin gold layer before examination. The notched Izod impact tests were performed with $80 \times 10$ $\times 4 \mathrm{~mm}$ specimens via a Shenzhen Suns PTM1251-B impact tester (Suns, Shenzhen, China) according to GB/T 1843-2008. The notched impact strength $\left(a_{i N}\right)$ of the samples was calculated by Equation $(1) . E_{c}$ is the corrected samples fracture absorption energy, $h$ is the thickness of samples and $b_{N}$ is the remaining width of the samples.

$$
a_{i N}=\frac{E_{c}}{h * b_{N}} * 10^{3}
$$

The tensile tests were measured using a Shenzhen Suns UTM6104 electronic universal tester (Suns, Shenzhen, China) with $5 \mathrm{~mm} / \mathrm{min}$ in accordance with GB/T 1040.3-2006. Tensile strength and elongation at break were performed by Equations (2) and (3). $\Sigma$ is the tensile strength, $P$ is the breaking load, and $b$ and $d$ are the width and thickness of samples. $E$ is the elongation at break. $G_{0}$ is the original gauge length of specimens and $G$ is the mark line distance at break. At least seven specimens were tested, and the average values were reported.

$$
\begin{gathered}
\Sigma=\frac{P}{b d} \\
E=\frac{G-G_{0}}{G_{0}} \times 100 \%
\end{gathered}
$$

\section{Results and Discussion}

\subsection{Limiting Oxygen Index and Vertical Burning Rating Test}

Flame retardant properties of PLA/HABP-DOPO blends were investigated through LOI and UL-94 tests. The results of LOI, UL-94 rating and dripping behavior of PLA blends are summarized in Table 1. It can be seen that pure PLA has a low LOI and exhibits high combustion and heavy dripping. LOI values markedly increased to $22.1,25.1$ and 28.5 with addition of 15,20 and $25 \mathrm{wt} \%$ HABP-DOPO. The increased LOI values show that burning behavior is restrained during flammation in higher oxygen conditions. HABP-DOPO promotes formation of a wrapped carbon layer during the combustion process, suppresses dripping of the PLA matrix and inhibits transfer of heat and oxygen into the inner substrate, which is the main reason for the higher LOI value [30]. Addition of HABP-DOPO can also decrease burning time significantly. Neat PLA cannot self-extinguish due to the low melt strength of PLA resin during combustion, while the UL-94 rating of the PLA blend with $25 \mathrm{wt} \%$ HABP-DOPO reaches V-0 level, and dripping behavior is clearly inhibited. With addition of HABP-DOPO, dripping of blends was inhibited. There was no dripping when the amount of HABP-DOPO was $25 \%$. Results demonstrate that HABP-DOPO not only has a good effect on the dripping behaviors of PLA blends during combustion but also leads to enhancement of LOI values at higher flame retardant concentrations.

Table 1. The limiting oxygen index (LOI) values and vertical burning (UL-94) rating of PLA and its blends.

\begin{tabular}{ccccc}
\hline & LOI (\%) & UL-94 & Dripping & Ignition \\
\hline PLA & 18.5 & $\mathrm{NR}$ & $\mathrm{Y}$ & $\mathrm{Y}$ \\
PLA/15 wt $\%$ HABP-DOPO & 22.1 & $\mathrm{~V}-1$ & $\mathrm{Y}$ & $\mathrm{Y}$ \\
PLA/20 $\mathrm{t} \%$ HABP-DOPO & 25.1 & $\mathrm{~V}-1$ & $\mathrm{Y}$ & $\mathrm{Y}$ \\
PLA/25 $\mathrm{w} \%$ HABP-DOPO & 28.5 & $\mathrm{~V}-0$ & $\mathrm{~N}$ & $\mathrm{~N}$ \\
\hline
\end{tabular}

\subsection{Thermogravimetric Analysis}

Thermal stability of HABP-DOPO, neat PLA and its blends under nitrogen atmosphere are characterized by TGA and derivative thermogravimetry (DTG) in Figure 2. The data obtained from 
TGA and DTG curves for PLA and its blends are illustrated in Table 2. It can be seen that HABP-DOPO shows very high thermal stability. The initial decomposition temperature of HABP-DOPO is about $326.7^{\circ} \mathrm{C}$ (based on $5 \%$ weight loss). According to DTG curves, the main peak of thermal degradation is about $476.8^{\circ} \mathrm{C}$, which can be attributed to the bisphenol structure and the $\mathrm{P}=\mathrm{N}$ six-membered ring. Based on the TGA curve of the PLA blend with $25 \mathrm{wt} \%$ HABP-DOPO, its residue char at 500, 600, 700 and $800{ }^{\circ} \mathrm{C}$ is $17.4,15.4,15.0$ and $14.4 \mathrm{wt} \%$, respectively, while that of the neat PLA is $0.026 \mathrm{wt} \%$ at $400{ }^{\circ} \mathrm{C}$. These results indicate that the PLA/HABP-DOPO blend presents higher thermal stability and has more char over $360^{\circ} \mathrm{C}$.
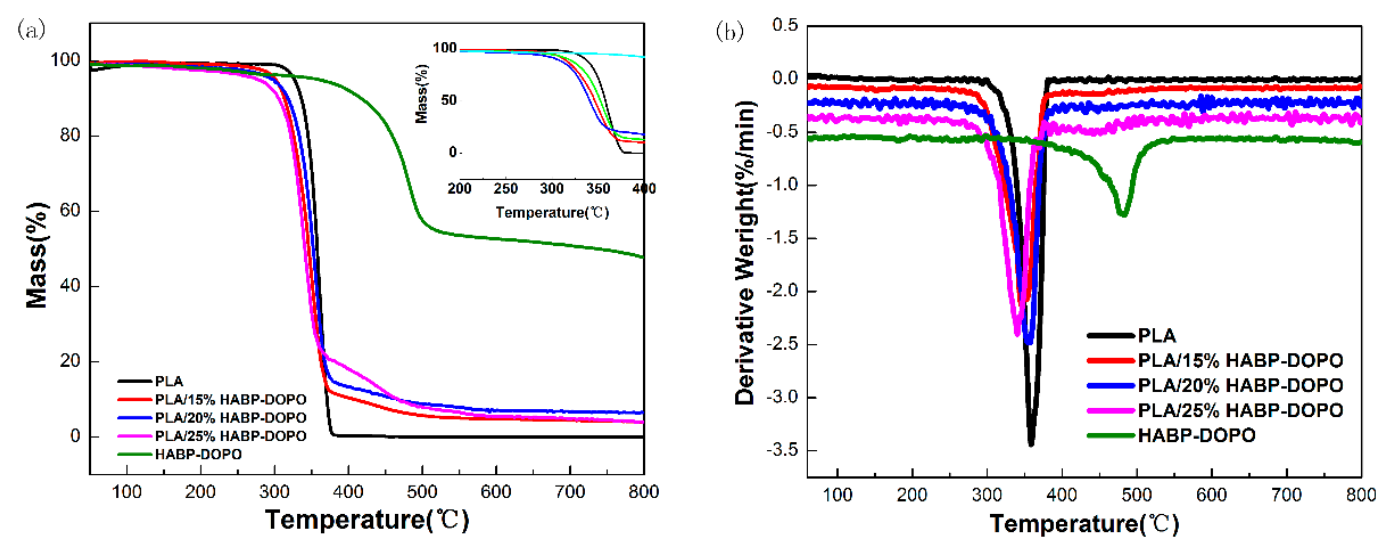

Figure 2. TGA and DTG curves of HABP-DOPO, neat PLA and PLA/HABP-DOPO blends under nitrogen gas atmosphere. (a) TGA curves and (b) DTG curves.

Table 2. Thermal properties of HABP-DOPO, neat PLA and PLA/HABP-DOPO blends.

\begin{tabular}{|c|c|c|c|c|}
\hline & $T_{5 \%}\left({ }^{\circ} \mathrm{C}\right)$ & $T_{\max }\left({ }^{\circ} \mathrm{C}\right)$ & $T_{25 \%}\left({ }^{\circ} \mathrm{C}\right)$ & Residue $(w t \%)$ at $800^{\circ} \mathrm{C}$ \\
\hline PLA & 326.7 & 357.2 & 348.2 & 0 \\
\hline HABP-DOPO & 359.4 & 476.8 & 470.3 & 47.7 \\
\hline PLA/15 wt $\%$ HABP-DOPO & 301.4 & 344.5 & 330.3 & 3.50 \\
\hline PLA/20 wt $\%$ HABP-DOPO & 297.5 & 352.3 & 332.0 & 8.68 \\
\hline PLA/25 wt $\%$ HABP-DOPO & 307.6 & 339.2 & 337.9 & 14.43 \\
\hline
\end{tabular}

It can be observed from DTG curves that PLA displays one-step degradation behavior, and PLA/ HDBP-DOPO blends exhibit two-steps processes. With the content of flame retardant increasing, the maximum decomposition temperature $\left(T_{\max }\right)$ of the blends decreases gradually and the residue increases. This indicates that addition of HABP-DOPO has an obvious effect on thermal stability and degradation behaviors of PLA. The onset degradation temperature $\left(T_{5 \%}\right)$ of PLA/HABP-DOPO blends is lower than that of neat PLA due to the relatively low decomposition temperature of HABP-DOPO. Acid products of decomposed phosphaphenanthrene in HABP-DOPO promoted early degradation of PLA at the lower temperature. The lower appropriate decomposing temperature and pyrolysis products with quenching effect of HABP-DOPO all facilitated the flame retardant effect of HABP-DOPO on PLA. Moreover, as the temperature increased, the protective layer constructed by the sample in the early stage of heating also played a role in delaying the degradation process of the PLA sample [30,31].

\subsection{Differential Scanning Calorimetry Test}

Differential scanning calorimetry (DSC) curves of PLA and its blends are depicted in Figure 3, and detailed results of DSC are summarized in Table 3. It can be seen from Table 3 that the glass transition temperature $\left(T_{g}\right)$ of PLA/HABP-DOPO blends increased gradually with the content of HABP-DOPO increasing. As for the blend with $25 \mathrm{wt} \%$ HABP-DOPO, $T_{g}$ of the PLA blends has increased from 59.9 to $62.6{ }^{\circ} \mathrm{C}$. An independent $T_{g}$ can be observed in DSC curves of all PLA/HABP-DOPO blends in Figure 3 , indicating that there is no interface slippage between flame retardant and PLA matrix [32]. 


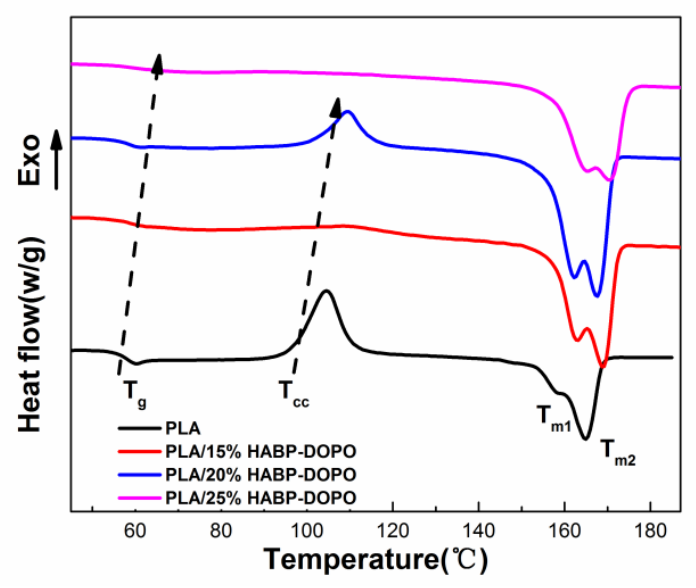

Figure 3. DSC curves of PLA and its blends.

Table 3. Detailed results of DSC of PLA and its blends.

\begin{tabular}{cccccccc}
\hline Sample & $\boldsymbol{T}_{\boldsymbol{g}}\left({ }^{\circ} \mathbf{C}\right)$ & $\boldsymbol{T}_{\boldsymbol{c c}}\left({ }^{\circ} \mathbf{C}\right)$ & $\boldsymbol{\Delta} \boldsymbol{H}_{\boldsymbol{c}}(\mathbf{J} / \mathbf{g})$ & $\boldsymbol{T}_{\boldsymbol{m} \mathbf{1}}\left({ }^{\circ} \mathbf{C}\right)$ & $\boldsymbol{T}_{\boldsymbol{m} \mathbf{2}}\left({ }^{\circ} \mathbf{C}\right)$ & $\Delta \boldsymbol{H}_{\boldsymbol{m} \mathbf{1}}(\mathbf{J} / \mathbf{g})$ & $\boldsymbol{X}_{\boldsymbol{c}}(\mathbf{\%})$ \\
\hline PLA & 59.9 & 107.7 & 35.46 & 150.1 & 168.2 & 49.91 & 53.3 \\
PLA/FR15 & 62.6 & 109.8 & 1.583 & 163.2 & 168.7 & 29.34 & 36.8 \\
PLA/FR20 & 60.9 & 109.5 & 8.907 & 162.7 & 167.2 & 35.49 & 47.3 \\
PLA/FR25 & 62.6 & - & 1.668 & 165.6 & 170.6 & 26.17 & 37.2 \\
\hline
\end{tabular}

Addition of HABP-DOPO can improve the cold crystallization temperature $\left(T_{c c}\right)$ of PLA and weaken its non-isothermal crystallization ability. The reason for the disappearance of $T_{\mathrm{cc}}$ is that the induction effect of the flame retardant accelerates crystallization rate and the crystal formation is more complete. For PLA/25\%HABP-DOPO blends, formation of aggregated particles in the polymeric matrix during melt processing reduces the nucleation point and makes crystallization incomplete: that is why the $T_{c c}$ peak reappears. Because HABP-DOPO as a dispersed phase affects the integrity of the PLA crystal and prevents regular accumulation of molecular chains, crystallinity $\left(X_{\mathcal{c}}\right)$ of PLA decreases. With increase of HABP-DOPO content in the blends, the main melting peak $\left(T_{m 2}\right)$ gradually weakened. Gradual addition of HABP-DOPO will reduce the ability of the material to form a crystal structure, resulting in a decrease in crystallinity of the composite material, which is manifested as a decrease in heat of crystallization $\left(\Delta H_{c}\right)$ and heat of melting $\left(\Delta H_{m}\right)$ of the composite material.

\subsection{Cone Calorimetry Test}

In order to evaluate the fire hazard under real fire conditions, cone calorimeter tests are conducted to investigate the flame retardant and burning behaviors of PLA/HABP-DOPO blends. Total heat release (THR), heat release rate (HRR) and total smoke release (TSR) curves of PLA and its blends are presented in Figures 4-6. Partial characteristic parameters, such as the time to ignition (TTI), peak of heat release rate (pk-HRR), average value of heat release rate (av-HRR), total heat release (THR), effective heat of combustion (EHC) and average value of mass loss rate (av-MLR) are summarized in Table 4. Digital photos of the blends after the cone calorimetry test are shown in Figure 7.

THR refers to total heat release of the materials released from ignition to flame extinction under preincident heat flow intensity. The THR value of neat PLA is $72.15 \mathrm{MJ} / \mathrm{m}^{2}$ and decreased with addition of HABP-DOPO. When the HABP-DOPO content was 15, 20 and $25 \mathrm{wt} \%$, the THR values of PLA/HABP-DOPO blends were $60.85,59.43$ and $43.07 \mathrm{MJ} / \mathrm{m}^{2}$, respectively. The slopes of THR curves represent the flame diffusion rate of the material [33]. With the content of HABP-DOPO increasing, the slopes of PLA/HABP-DOPO blends gradually decrease and combustion of the flame has begun to slow down. The slope of PLA blend with $25 \mathrm{wt} \%$ HABP-DOPO shows the lowest value and exhibits good fire resistance. 
HRR refers to heat release rate per unit area after a material is ignited under a preset incident heat flux. As shown in Table 4, when the content of HABP-DOPO is increased from 0 to $25 \mathrm{wt} \%$, the pk-HRR value is reduced to $271.38 \mathrm{~kW} / \mathrm{m}^{2}$ from $336.86 \mathrm{~kW} / \mathrm{m}^{2}$.

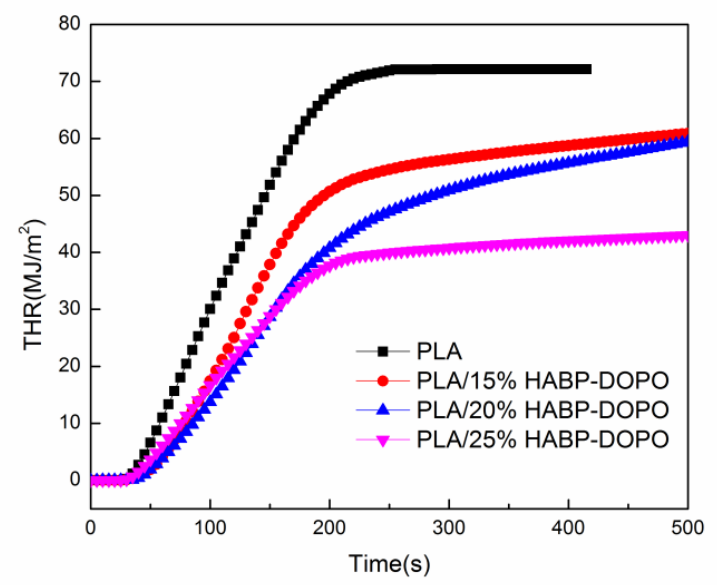

Figure 4. Total heat release (THR) curves of PLA and PLA/HABP-DOPO blends.

Table 4. Cone calorimetric test data for PLA/HABP-DOPO blends.

\begin{tabular}{|c|c|c|c|c|c|c|c|}
\hline Sample & $\begin{array}{l}\text { TTI } \\
\text { (s) }\end{array}$ & $\begin{array}{l}\text { Pk-HRR } \\
\left(\mathrm{kW} / \mathrm{m}^{2}\right)\end{array}$ & $\begin{array}{l}\text { Av-HRR } \\
\left(\mathrm{kW} / \mathrm{m}^{2}\right)\end{array}$ & $\begin{array}{c}\text { THR } \\
\left(\mathrm{MJ} / \mathrm{m}^{2}\right)\end{array}$ & $\begin{array}{c}\text { TSR } \\
\left(\mathrm{m}^{2} / \mathrm{m}^{2}\right)\end{array}$ & $\begin{array}{l}\text { Av-MLR } \\
g /\left(s \cdot m^{2}\right)\end{array}$ & $\begin{array}{c}\text { EHC } \\
(\mathrm{MJ} / \mathrm{kg})\end{array}$ \\
\hline PLA & 53 & 336.86 & 263.42 & 72.15 & 22.2 & 20.58 & 74.47 \\
\hline PLA/15 wt $\%$ HABP-DOPO & 39 & 322.9 & 241.35 & 63.7 & 860.6 & 12.64 & 70.14 \\
\hline PLA/20 wt $\%$ HABP-DOPO & 36 & 303.2 & 231.7 & 53.8 & 909.9 & 18.78 & 73.36 \\
\hline PLA/25 wt $\%$ HABP-DOPO & 32 & 271.38 & 212.54 & 42.9 & 970.2 & 25.87 & 79.15 \\
\hline
\end{tabular}

Figure 5 shows HRR curves of PLA and its blends. Neat PLA had only one peak during the combustion process, while PLA/HDBP-DOPO blends presents two peaks. HRR values corresponding to two peaks are obviously lower than that of one peak of neat PLA. The first peak appears at 80-100 s, which can be attributed to rapid decomposition of HABP-DOPO on the surface which can cause degradation of the PLA matrix, which in turn induces the surface temperature of the blends to rise rapidly and generates heat released through combustion. The second peak appears around $150 \mathrm{~s}$ corresponding to burning of PLA/HABP-DOPO blends.

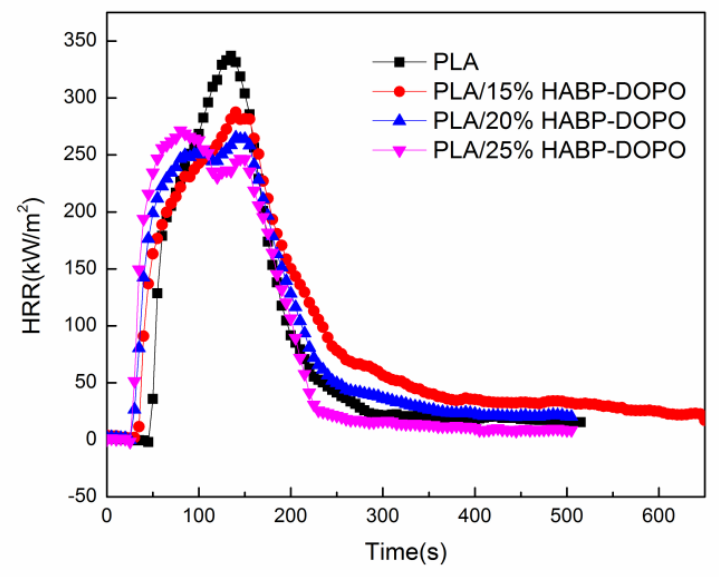

Figure 5. Heat release rate (HRR) curves of PLA and PLA/HABP-DOPO blends.

TTI of PLA/HABP-DOPO blends become short gradually with the content of HABP-DOPO increasing because of quick decomposition of HABP-DOPO. Effective heat of combustion (EHC) 
can evaluate the contribution of effective combustion components to heat release that exist in the gas phase during the combustion process [34]. As the content of HABP-DOPO increases, av-EHC decreases slightly, which indicates that the content of effective combustion components in the product was reduced.

Total smoke release (TSR) refers to the total cumulative amount of smoke generated when a unit sample area of a material is burned. As shown in Figure 6, with the increase of HABP-DOPO, TSR increases gradually, demonstrating that HABP-DOPO plays an important role in gas phase flame retardancy. Elevated TSR can reduce concentration of oxygen by diluting concentration of oxygen and taking away heat generated during the combustion process [35].

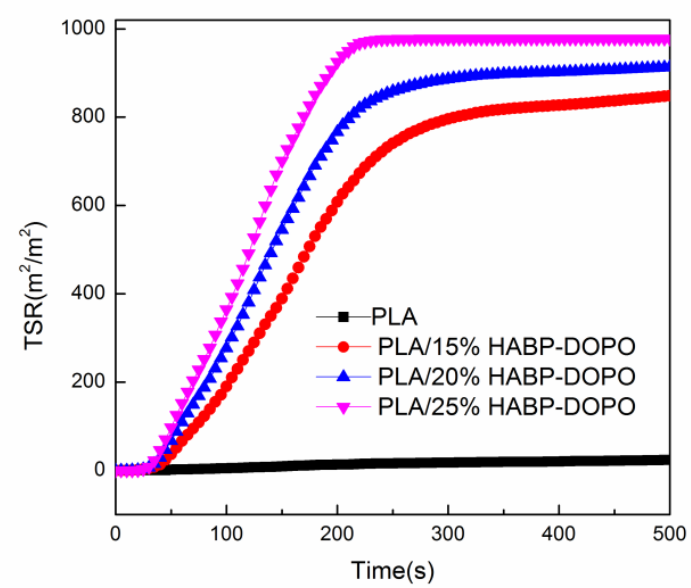

Figure 6. Total smoke release (TSR) curves of PLA and PLA/HABP-DOPO blends.

The residual char after the cone calorimetry test can intuitively show the flame retardant performance of polymer blends. Figure 7 shows photos of PLA/HABP-DOPO blends after the cone calorimetry test. The residual char increases with the content of HABP-DOPO increasing. This can be attributed to the following reasons. HABP-DOPO plays the role of a carbon-forming agent, and good dispersion of flame retardant in the PLA matrix also provides more carbon formation sites. In conclusion, addition of HABP-DOPO is beneficial to formation of a carbon layer in the solid phase.
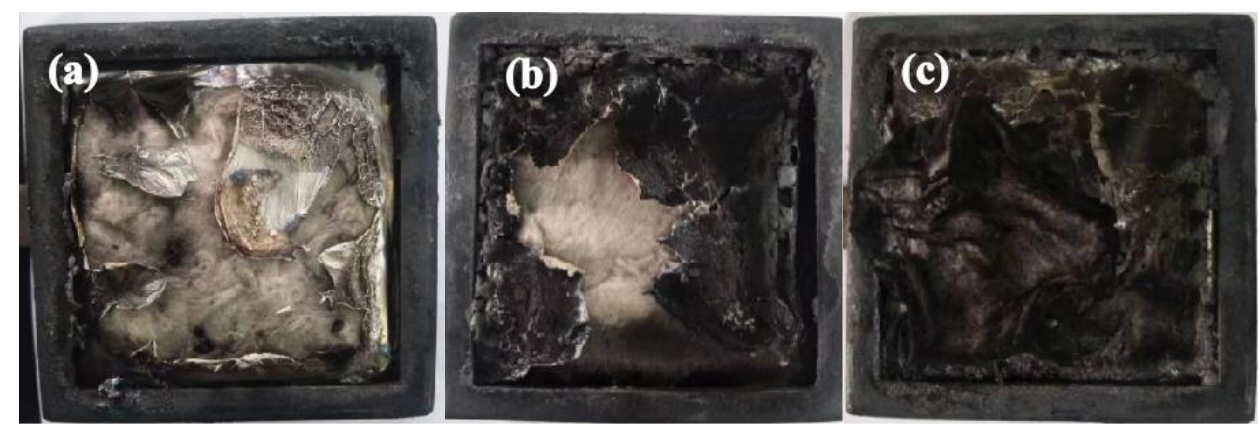

Figure 7. Digital photos of PLA/HABP-DOPO blends after cone calorimetry test: (a) pure PLA, (b) PLA/15\%HABP-DOPO and (c) PLA/25\%HABP-DOPO.

\subsection{Morphologies of the Residue Char}

It is well known that morphologies of the char layer play a very important role in the performance of flame retardancy, profiting from prevention of heat transfer, flame spreading and droplet generation. In order to clarify the relationship between flame retardant performance and the microstructure of intumescing chars, the intumescing char residue of PLA/HABP-DOPO blends after cone calorimeter tests were examined using SEM as shown in Figure 8. 


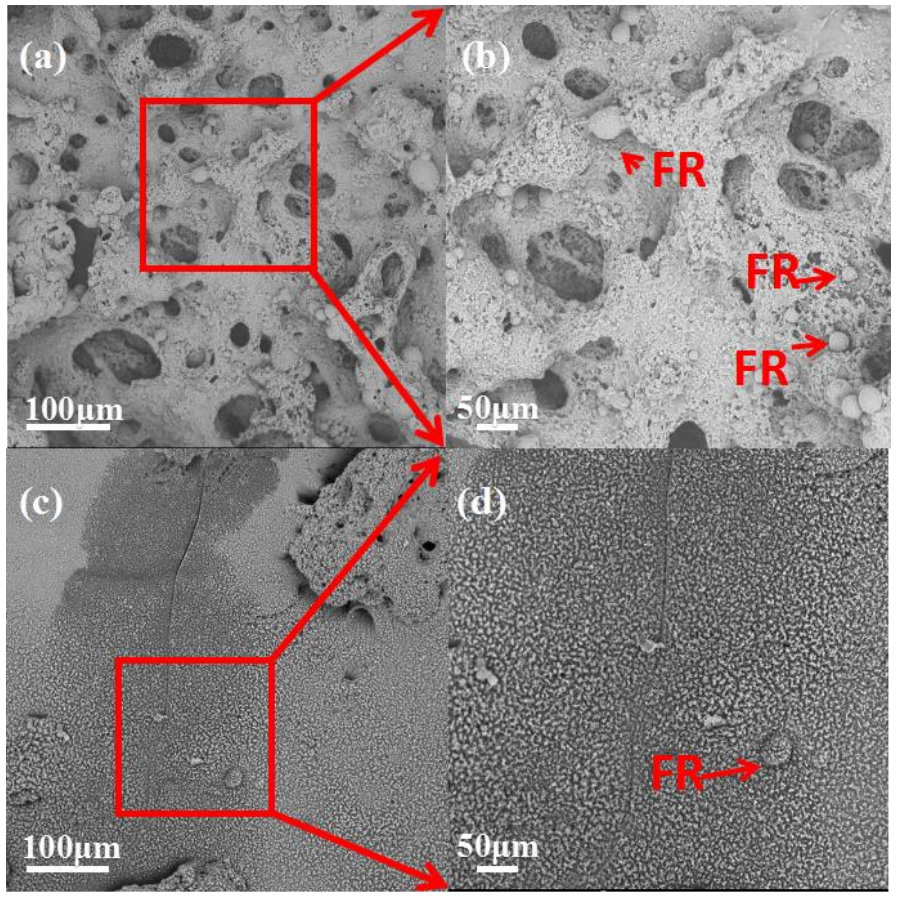

Figure 8. SEM images of PLA/HABP-DOPO blends after cone calorimeter tests. (a), (b) PLA/15 wt $\%$ HABP-DOPO and (c), (d) PLA/25 wt \% HABP-DOPO.

In Figure $8 \mathrm{a}, \mathrm{b}$ for the PLA blend with $15 \mathrm{wt} \%$ HABP-DOPO, the surface of the char layer has many big holes and several cracks. The char layer reveals slight foaming, but the foams are not adequately dense due to insufficient char formation or less condensed char during the burning process. The exchange channels, originated from heat and gas generated during the combustion process, are not conducive to flame retardancy. These factors determine poor flame retardancy performance of this blend.

However, the residue of the PLA blend with $25 \mathrm{wt} \%$ HABP-DOPO exhibits denser foams with intumescent and compact morphologies. This structure of char can hinder both mass and heat transfer to effectively retard degradation of the PLA matrix and block gas and heat exchange during the combustion process. Results indicate that the carbon layer formed by $25 \mathrm{wt} \%$ HABP-DOPO in the solid phase is more stable and can withstand the impact of high temperature radiation and gas release [30]. A large amount of HABP-DOPO plays a role in solid phase flame retardancy. It also can be observed from Figure 8 that flame retardant particles are presented on the surface of the residual char. This is because the flame retardant gradually migrates, deposits on the surface of the material and forms a wrinkled residual char during combustion of the PLA blends. Flame retardants promote formation of the residual char.

\subsection{FTIR of PLA/HABP-DOPO Blends}

Infrared spectroscopy is used to characterize the existence of hydrogen bonds in polymer systems. The $\mathrm{C}=\mathrm{O}$ groups of PLA are generally considered to be a hydrogen bonding acceptor, while the $\mathrm{OH}$ groups of HABP-DOPO are considered to be a hydrogen-bonded donor. Figure 9 shows FTIR spectra of neat PLA and its blend. Compared with neat PLA, the peaks of PLA/HABP-DOPO blend have changed significantly. A large number of -OH groups of HABP-DOPO can produce strong intermolecular hydrogen bonds: $\mathrm{O}-\mathrm{H} \cdots \mathrm{O}$ with the $\mathrm{O}$ atoms in PLA, thereby improving their compatibility. Due to in-plane bending, the $\mathrm{COOH}$ peak of pure PLA at $1360.7 \mathrm{~cm}^{-1}$ is split into 1360.7 and $1382.1 \mathrm{~cm}^{-1}$ bands. The narrow symmetrical peak (at $1757 \mathrm{~cm}^{-1}$ ), corresponding to the $\mathrm{C}=\mathrm{O}$ stretching mode of the ester in PLA, becomes wider and eventually splits into two bands. It is attributed to addition of 
HABP-DOPO. The amide peak shows obvious weak splitting and a new weak peak gradually forms at the low wave number of the amide peak [36].

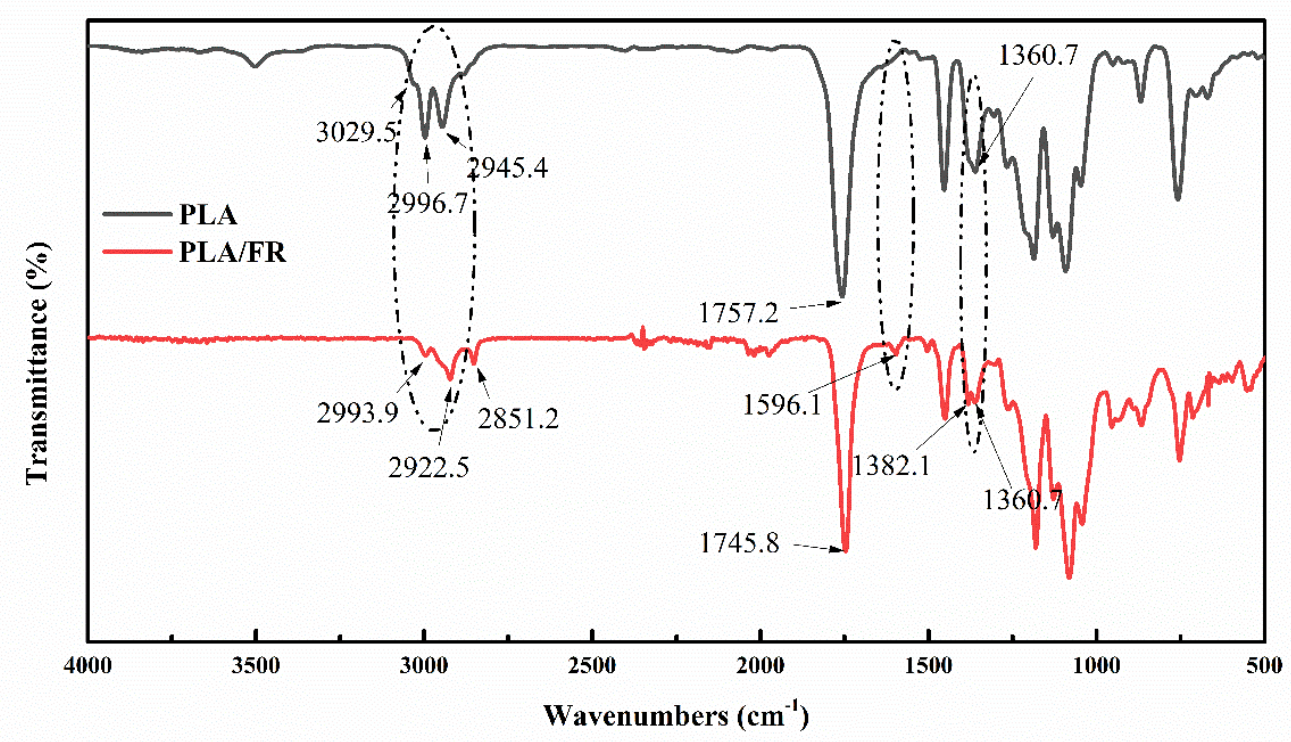

Figure 9. FTIR of neat PLA and its blend with $25 \mathrm{wt} \%$ HABP-DOPO.

\subsection{Dispersion of Flame Retardant in PLA Matrix}

Morphologies and distributions of the additive-type flame retardant in PLA play an important role in mechanical properties as well as flame retardancy. The SEM micrograph of the cryo-fracture of PLA/HABP-DOPO blends is displayed in Figure 10. It is obvious that HABP-DOPO particle agglomerations cannot be observed in SEM micrographs with different magnifications, which meant a uniform distribution of the flame retardant particles in the PLA matrix [22,37].

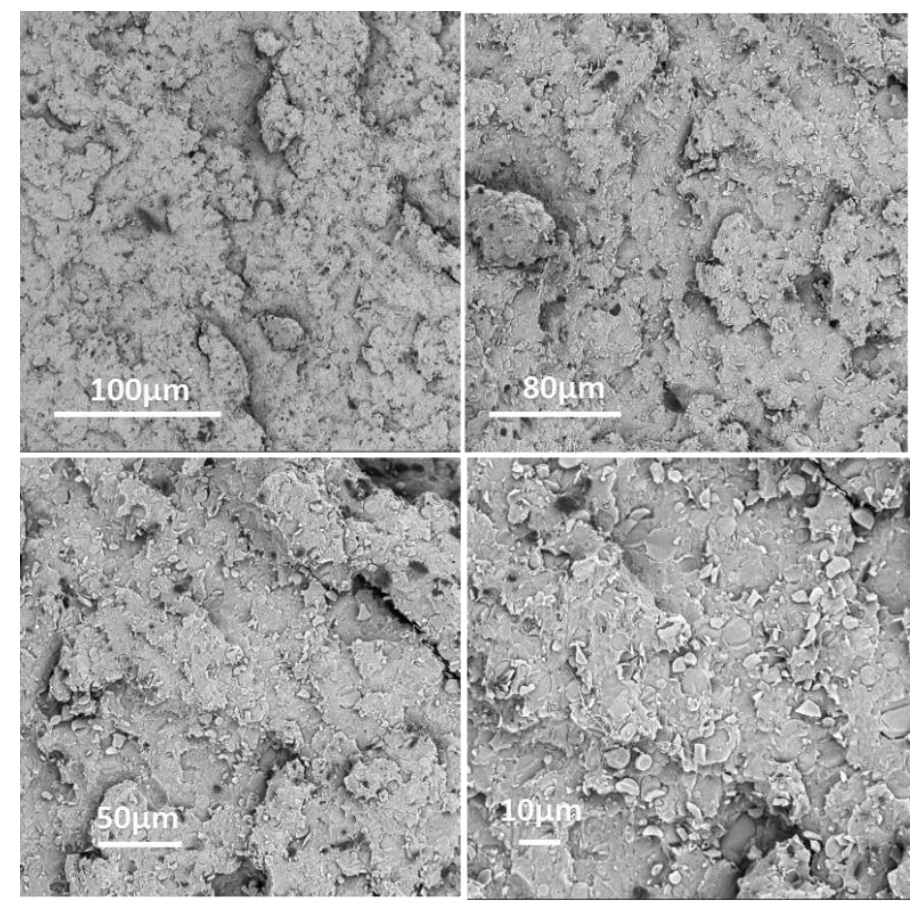

Figure 10. SEM micrograph of the cryo-fracture of the PLA/25\% HABP-DOPO composite. 


\subsection{Mechanical Properties Test}

Usually, introduction of flame retardants to the polymer can lead to decline of mechanical properties because of their poor compatibility. Figure 11 presents impact properties, tensile properties and elongation at break properties of neat PLA and PLA/HABP-DOPO blends. The Izod impact strength of PLA was $4.51 \mathrm{~kJ} / \mathrm{m}^{2}$ and its blends are 15, 20 and $25 \mathrm{wt} \%$. For HABP-DOPO the Izod impact strengths were $4.37,4.29$ and $4.21 \mathrm{~kJ} / \mathrm{m}^{2}$, respectively. Compared to pure PLA, addition of HABP-DOPO has little effect on the impact properties of PLA, which could be attributed to effective dispersion of flame retardants. Hydrogen bonding between the hydroxyl-rich flame retardant and the PLA matrix is another important reason for good compatibility. Similar to Izod impact strength, tensile strength and elongation at break of the blends change little with the content of HABP-DOPO increasing. Therefore, HABP-DOPO is a powerful candidate for PLA because PLA/HABP-DOPO blends exhibit balanced mechanical properties and flame retardancy.
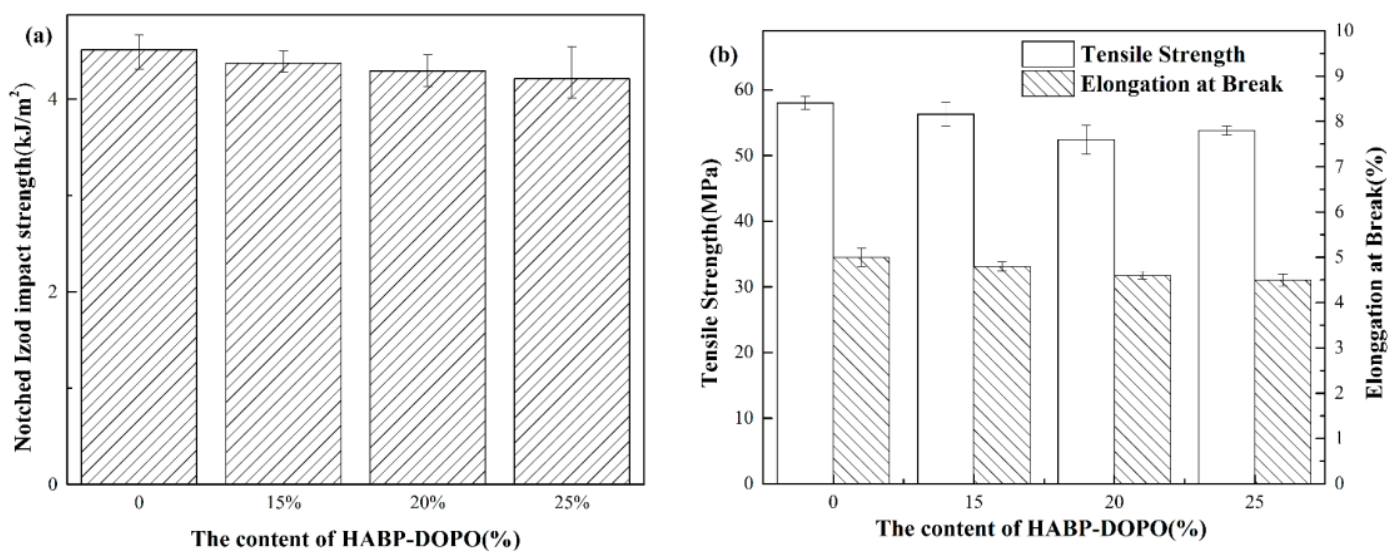

Figure 11. Mechanical properties of PLA and its blends: (a) notched impact strength and (b) tensile strength and elongation at break.

\subsection{Mechanism of Flame Retardant in PLA Matrix}

By comparing effective heat of combustion (EHC) of neat PLA and its blends, we can evaluate whether the flame retardant mechanism is mainly in the gas phase or solid phase. If the system is a gas phase flame retardant mechanism, the flame retardant burned will release free radicals in the gas phase. These free radicals will stop the combustion reaction, PLA blends will not completely burn and the EHC of PLA blends will be lower than that of neat PLA. Similarly, if the EHC of PLA blends is higher than that of the PLA matrix, the flame retardants exhibit the solid phase flame retardant mechanism.

Figure 12 shows EHC curves of PLA and PLA/HABP-DOPO blends. It can be seen that in the first stage of combustion, the solid phase is mainly flame retardant and the DOPO in HABP-DOPO is a carbon-forming agent at a high temperature stage. The reason is that stability of the phosphazene structure is higher than that of the phosphaphenanthrene structure. Based on analysis of microscopic morphology after cone calorimetry, a large amount of residual carbon forms during the flame retardant process in the condensed phase and can act as heat insulation and an oxygen barrier to protect the matrix. It can be seen that most of it presents a relatively complete, dense and thick carbon layer structure, and there are also relatively fluffy, porous or even expanded morphologies, which are mainly caused by emission of flame retardant gases such as ammonia during the combustion process. In the second stage of combustion, HABP-DOPO is thermally decomposed to form a series of radicals containing $\mathrm{P}$ such as $\mathrm{Ph}-\mathrm{O}$ and $\mathrm{HPO}_{2}$, which can play a role in promoting dehydration and accelerating char formation. At the same time, non-combustible gases such as $\mathrm{NH}_{3}, \mathrm{H}_{2} \mathrm{O}$ and $\mathrm{CO}_{2}$ will dilute $\mathrm{O}_{2}$ and gaseous fuel concentration in the combustion zone and exhibit good flame retardancy. As shown in Figure 13, the flame retardant mechanism of PLA/HABP-DOPO blends should be the synergistic flame retardancy of solid phase and gas phase [38,39]. 


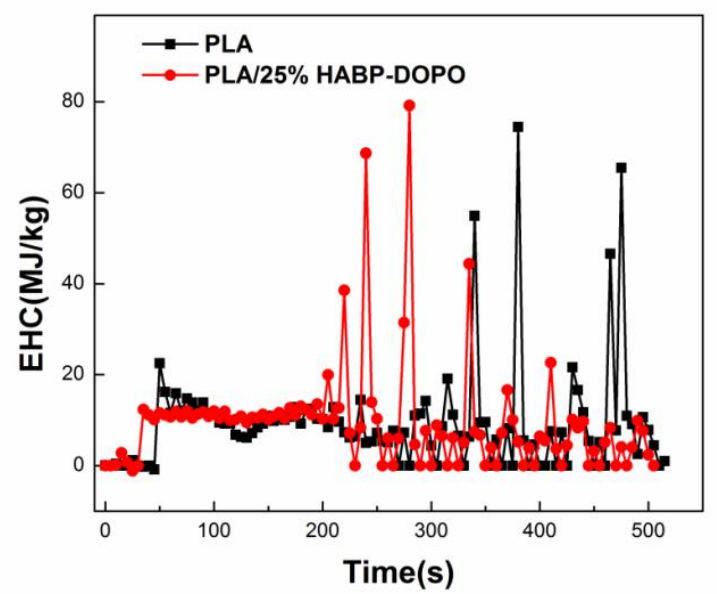

Figure 12. Effective heat of combustion (EHC) curves of PLA and PLA/HABP-DOPO blends.

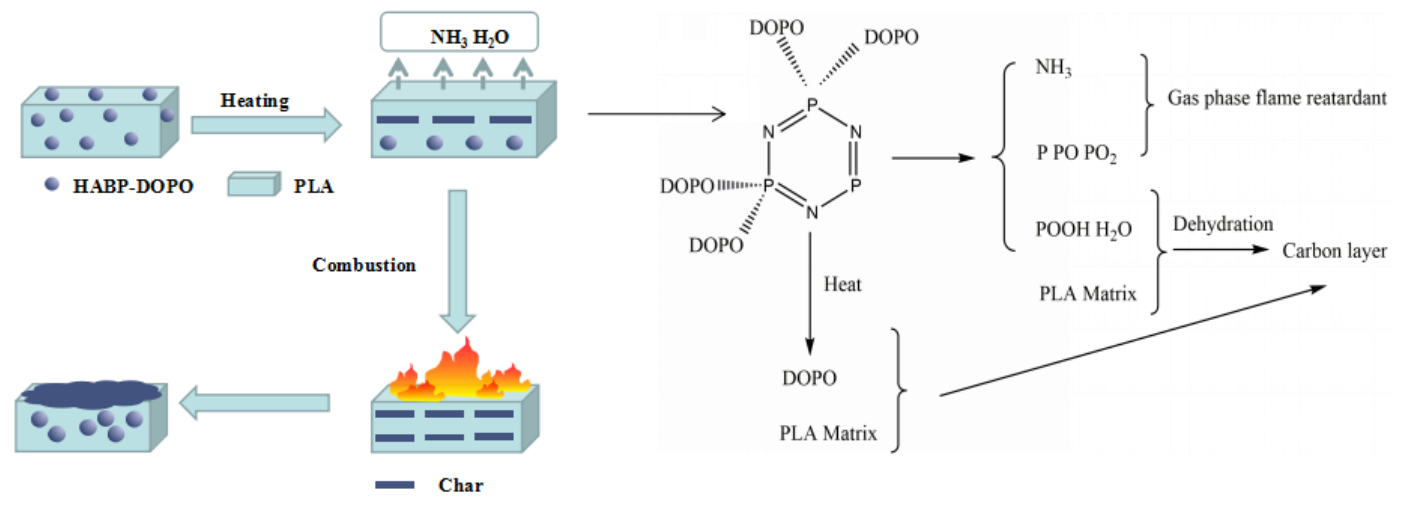

Figure 13. Flame retardant mechanism of PLA/HABP-DOPO blends.

\section{Conclusions}

A novel flame retardant (HABP-DOPO) containing phosphazene and phosphaphenanthrene was synthesized and blended with PLA to improve its flame retardancy. The PLA blend with $25 \mathrm{wt} \%$ HABP-DOPO had a $28.5 \%$ LOI value and UL-94 V-0 flammability rating. The pk-HRR, THR and av-MLR values of PLA/HABP-DOPO blends obtained from CCT reduced dramatically compared to pure PLA. The onset degradation temperature of PLA/HABP-DOPO blends decreased with the content of HABP-DOPO increasing. The morphologies of the char residues had a continuous, compact and intumescent outer surface, hindered heat transmission and gas diffusion, and exhibited good flame retardancy. Furthermore, PLA/HABP-DOPO blends maintain the same level of mechanical properties as neat PLA. Therefore, HABP-DOPO is a powerful flame retardant. The flame retardant mechanism of PLA/HABP-DOPO blends should be the synergistic flame retardancy of solid and gas phases.

Author Contributions: Data curation, Z.W.; funding acquisition, M.N.; writing-original draft, Z.Z. and writing-review and editing, W.W. All authors have read and agreed to the published version of the manuscript.

Funding: The authors thank the National Natural Science Foundation of China (51373157) of MOST for financial support.

Conflicts of Interest: The authors declare no conflict of interest. 


\section{References}

1. Armentano, I.; Bitinis, N.; Fortunati, E.; Mattioli, S.; Rescignano, N.; Verdejo, R.; Lopez-Manchado, M.; Kenny, J. Multifunctional nanostructured PLA materials for packaging and tissue engineering. Prog. Polym. Sci. 2013, 38, 1720-1747. [CrossRef]

2. Emami, F.; Yazdi, S.J.M.; Na, D.H. Poly(lactic acid)/poly(lactic-co-glycolic acid) particulate carriers for pulmonary drug delivery. J. Pharm. Investig. 2019, 49, 427-442. [CrossRef]

3. Wang, L.-X.; Wang, N.; Zhou, Y.; Zhang, Y.; Li, Q.; Shen, C. Fabrication of open-porous PCL/PLA tissue engineering scaffolds and the relationship of foaming process, morphology, and mechanical behavior. Polym. Adv. Technol. 2019, 30, 2539-2548. [CrossRef]

4. Zuo, L.; Fan, W.; Zhang, Y.; Zhang, L.; Gao, W.; Huang, Y.; Liu, T. Graphene/montmorillonite hybrid synergistically reinforced polyimide composite aerogels with enhanced flame-retardant performance. Compos. Sci. Technol. 2017, 139, 57-63. [CrossRef]

5. Botiz, I.; Darling, S.B. Self-Assembly of Poly(3-hexylthiophene)-block-polylactide Block Copolymer and Subsequent Incorporation of Electron Acceptor Material. Macromolecules 2009, 42, 8211-8217. [CrossRef]

6. Bocz, K.; Domonkos, M.; Igricz, T.; Kmetty, Á.; Bárány, T.; Marosi, G. Flame retarded self-reinforced poly(lactic acid) composites of outstanding impact resistance. Compos. Part. A: Appl. Sci. Manuf. 2015, 70, $27-34$. [CrossRef]

7. Yang, J.-P.; Liao, Q.; Zhou, J.; Jiang, X.; Wang, X.-H.; Zhang, Y.; Jiang, S.-D.; Yan, S.-K.; Li, L. What Determines the Lamellar Orientation on Substrates? Macromolecules 2011, 44, 3511-3516. [CrossRef]

8. Cheng, K.-C.; Lin, Y.-H.; Guo, W.; Chuang, T.-H.; Chang, S.-C.; Wanga, S.-F.; Don, T.-M. Flammability and tensile properties of polylactide nanocomposites with short carbon fibers. J. Mater. Sci. 2014, 50, 1605-1612. [CrossRef]

9. Sun, F.; Yu, T.; Hu, C.; Li, Y. Influence of functionalized graphene by grafted phosphorus containing flame retardant on the flammability of carbon fiber/epoxy resin (CF/ER) composite. Compos. Sci. Technol. 2016, 136, 76-84. [CrossRef]

10. Ji, J.; Wang, L.; Yu, H.; Chen, Y.; Zhao, Y.; Zhang, H.; Amer, W.A.; Sun, Y.; Huang, L.; Saleem, M. Chemical Modifications of Chitosan and Its Applications. Polym. Technol. Eng. 2014, 53, 1494-1505. [CrossRef]

11. Mauldin, T.C.; Zammarano, M.; Gilman, J.W.; Shields, J.R.; Boday, D.J. Synthesis and characterization of isosorbide-based polyphosphonates as biobased flame-retardants. Polym. Chem. 2014, 5, 5139-5146. [CrossRef]

12. González, A.; Dasari, A.; Herrero, B.; Plancher, E.; Santarén, J.; Esteban, A.; Lim, S.-H. Fire retardancy behavior of PLA based nanocomposites. Polym. Degrad. Stab. 2012, 97, 248-256. [CrossRef]

13. Kanat, M.; Eren, T. Synthesis of phosphorus-containing flame retardants and investigation of their flame retardant behavior in textile applications. J. Appl. Polym. Sci. 2019, 136, 47935-47948. [CrossRef]

14. Adner, D.; Helmy, M.; Otto, T.; Schellenberg, J.; Schadewald, A. A macromolecular halogen-free flame retardant and its effect on the properties of thermoplastic polyesters. Fire Mater. 2018, 43, 169-174. [CrossRef]

15. Wang, J.; Ai, K.; Lu, L. Flame-retardant porous hexagonal boron nitride for safe and effective radioactive iodine capture. J. Mater. Chem. A 2019, 7, 16850-16858. [CrossRef]

16. Zhou, X.; Li, J.; Wu, Y. Synergistic effect of aluminum hypophosphite and intumescent flame retardants in polylactide. Polym. Adv. Technol. 2015, 26, 255-265. [CrossRef]

17. Zhao, X.; Gao, S.; Liu, G. A THEIC-based polyphosphate melamine intumescent flame retardant and its flame retardancy properties for polylactide. J. Anal. Appl. Pyrolysis 2016, 122, 24-34. [CrossRef]

18. Shi, X.; Ju, Y.; Zhang, M.; Wang, X. The intumescent flame-retardant biocomposites of poly(lactic acid) containing surface-coated ammonium polyphosphate and distiller's dried grains with solubles (DDGS). Fire Mater. 2017, 42, 190-197. [CrossRef]

19. Yan, Y.; Gu, X.; Li, L.; Li, H.; Sun, J.; Zhang, S. Preparation and characterization of intumescent flame retardant biodegradable poly(lactic acid) nanocomposites based on sulfamic acid intercalated layered double hydroxides. Fibers Polym. 2017, 18, 2060-2069. [CrossRef]

20. Lu, L.; Guo, N.; Qian, X.; Yang, S.; Wang, X.; Jin, J.; Shao, G. Thermal degradation and combustion behavior of intumescent flame-retardant polypropylene with novel phosphorus-based flame retardants. J. Appl. Polym. Sci. 2017, 135, 45962. [CrossRef] 
21. Qian, L.; Qiu, Y.; Sun, N.; Xu, M.; Xu, G.; Xin, F.; Chen, Y. Pyrolysis route of a novel flame retardant constructed by phosphaphenanthrene and triazine-trione groups and its flame-retardant effect on epoxy resin. Polym. Degrad. Stab. 2014, 107, 98-105. [CrossRef]

22. Xi, W.; Qian, L.; Qiu, Y.; Chen, Y. Flame-retardant behavior of bi-group molecule derived from phosphaphenanthrene and triazine groups on polylactic acid. Polym. Adv. Technol. 2015, 27, 781-788. [CrossRef]

23. Gu, L.; Qiu, J.; Yao, Y.; Sakai, E.; Yang, L. Functionalized MWCNTs modified flame retardant PLA nanocomposites and cold rolling process for improving mechanical properties. Compos. Sci. Technol. 2018, 161, 39-49. [CrossRef]

24. Chen, Y.; Wang, W.; Liu, Z.; Yao, Y.; Qian, L. Synthesis of a novel flame retardant containing phosphazene and triazine groups and its enhanced charring effect in poly(lactic acid) resin. J. Appl. Polym. Sci. 2016, 134, 44660-44668. [CrossRef]

25. Tang, G.; Deng, D.; Chen, J.; Zhou, K.; Zhang, H.; Huang, X.; Zhou, Z. The influence of organo-modified sepiolite on the flame-retardant and thermal properties of intumescent flame-retardant polylactide composites. J. Therm. Anal. Calorim. 2017, 130, 763-772. [CrossRef]

26. Pang, J.; Xianzhong, M.O.; Liu, Y. Preparation and characterization of flame retardant banana fiber reinforced PLA composites. Chem. Ind. Eng. Prog. 2015, 9, 1-6. [CrossRef]

27. Shi, X.; Peng, X.; Zhu, J.; Lin, G.; Kuang, T. Synthesis of DOPO-HQ-functionalized graphene oxide as a novel and efficient flame retardant and its application on polylactic acid: Thermal property, flame retardancy, and mechanical performance. J. Colloid Interface Sci. 2018, 524, 267-278. [CrossRef]

28. Zhang, M.; Luo, Z.; Zhang, J.; Chen, S.; Zhou, Y. Effects of a novel phosphorus-nitrogen flame retardant on rosin-based rigid polyurethane foams. Polym. Degrad. Stab. 2015, 120, 427-434. [CrossRef]

29. Carriedo, G.A.; Fernández-Catuxo, L.; Alonso, F.J.G.; Gómez-Elipe, P.; González, P.A. Preparation of a new type of phosphazene high polymers containing 2,2'-dioxybiphenyl groups. Macromolecules 1996, 29, 5320-5325. [CrossRef]

30. Jin, X.; Gu, X.; Chen, C.; Tang, W.; Li, H.; Liu, X.; Bourbigot, S.; Zhang, Z.; Sun, J.; Zhang, S. The fire performance of polylactic acid containing a novel intumescent flame retardant and intercalated layered double hydroxides. J. Mater. Sci. 2017, 52, 12235-12250. [CrossRef]

31. Jin, X.; Sun, J.; Zhang, J.S.; Gu, X.; Bourbigot, S.; Li, H.; Tang, W.; Zhang, S. Preparation of a novel intumescent flame retardant based on supramolecular interactions and its application in polyamide 11. ACS Appl. Mater. Interfaces 2017, 9, 24964-24975. [CrossRef] [PubMed]

32. Mazidi, M.M.; Edalat, A.; Berahman, R.; Hosseini, F.S. Highly-Toughened Polylactide- (PLA-) Based Ternary Blends with Significantly Enhanced Glass Transition and Melt Strength: Tailoring the Interfacial Interactions, Phase Morphology, and Performance. Macromolecules 2018, 51, 4298-4314. [CrossRef]

33. Zhang, J.; De Juan, S.; Esteban-Cubillo, A.; Santarén, J.; Wang, D.-Y. Effect of Organo-Modified Nanosepiolite on Fire Behaviors and Mechanical Performance of Polypropylene Composites. Chin. J. Chem. 2015, 33, 285-291. [CrossRef]

34. Qian, L.; Qiu, Y.; Wang, J.; Xi, W. High-performance flame retardancy by char-cage hindering and free radical quenching effects in epoxy thermosets. Polymer 2015, 68, 262-269. [CrossRef]

35. You, G.; Cheng, Z.; Peng, H.; He, H.-W. Synthesis and performance of a novel nitrogen-containing cyclic phosphate for intumescent flame retardant and its application in epoxy resin. J. Appl. Polym. Sci. 2014, 132, 6257-6267. [CrossRef]

36. Lin, Y.; Zhang, K.-Y.; Dong, Z.-M.; Dong, L.-S.; Li, Y.-S. Study of hydrogen-bonded blend of polylactide with biodegradable hyperbranched poly(ester amide). Macromolecules 2007, 40, 6257-6267. [CrossRef]

37. Zhang, N.; Lu, X. Mechanical, thermal and combustion properties of intumescent flame retardant biodegradable poly (lactic acid) composites. Plast. Rubber Compos. 2018, 47, 458-467. [CrossRef]

38. Zhang, F.; Gao, W.; Jia, Y.; Lu, Y.; Zhang, G. A concise water-solvent synthesis of highly effective, durable, and eco-friendly flame-retardant coating on cotton fabrics. Carbohydr. Polym. 2018, 199, 256-265. [CrossRef] 
39. Si, M.M.; Ding, S.; Hao, J.W.; Xu, L.S.; Du, J.X. Synergistic effect of NaNOSb2O3 and aluminium phosphinate on flame retardancy of PET. Acta Polym. Sin. 2013, 13, 1483-1491. [CrossRef]

Publisher's Note: MDPI stays neutral with regard to jurisdictional claims in published maps and institutional affiliations.

(C) 2020 by the authors. Licensee MDPI, Basel, Switzerland. This article is an open access article distributed under the terms and conditions of the Creative Commons Attribution (CC BY) license (http://creativecommons.org/licenses/by/4.0/). 